\title{
Review Article \\ Stem Cell Therapy for Lower Extremity Diabetic Ulcers: Where Do We Stand?
}

\author{
Mei Yang, ${ }^{1}$ Lingling Sheng, ${ }^{2}$ Tian R. Zhang, ${ }^{1}$ and Qingfeng $\mathrm{Li}^{2}$ \\ ${ }^{1}$ Division of Plastic Surgery, Southern Illinois University School of Medicine, Springfield, IL 62794, USA \\ ${ }^{2}$ Department of Plastic and Reconstructive Surgery, Shanghai Ninth People's Hospital, Shanghai Jiao Tong University School of \\ Medicine, Shanghai 200011, China \\ Correspondence should be addressed to Qingfeng Li; drliqingfeng@yahoo.cn
}

Received 19 November 2012; Revised 3 February 2013; Accepted 4 February 2013

Academic Editor: Richard Gomer

Copyright (C) 2013 Mei Yang et al. This is an open access article distributed under the Creative Commons Attribution License, which permits unrestricted use, distribution, and reproduction in any medium, provided the original work is properly cited.

The impairment of wound healing in diabetic patients is an important clinical problem affecting millions of patients worldwide. Various clinical and basic science studies show that stem cell therapy, as a regenerative medical therapy, can be a good solution. In this paper, we begin with an introduction of the cellular mechanism of the diabetic ulcer. We will then discuss the advantages and limitations of various stem cell therapies that have been under extensive recent study.

\section{Introduction}

The diabetic ulcer, a major complication of diabetes mellitus, has remained an important clinical challenge. Not only does it affect the physical and mental health of patients, but it is also an economic burden on our society. Now, the diagnosis and classification of diabetic ulcer is guided by the Wagner classification system and the University of Texas Diabetic Wound Classification system [1]. The standard clinical treatment of diabetic ulcer includes local wound care with dressing, virgous and repeated debridement of necrotic tissue, and offloading. Antibiotics will also be given if infection exists. However, the result is still far from satisfaction, and $14 \%-20 \%$ of patients with diabetic ulcer will end up with amputation $[1,2]$.

Various approaches have been developed for diabetic wound healing, but most of these approaches have centered on one facet of wound healing, such as inflammation or growth factors [3-5]. With a multifactorial etiology, therapy that focuses on one facet has limited therapeutic efficacy $[6,7]$. However, stem cell therapy has shown promise. Clinical and basic science studies show that these therapies can provide a comprehensive solution by addressing multiple factors during diabetic wound healing, including cell proliferation, extracellular matrix (ECM) synthesis, growth factor release, and vascularization. In this paper, we begin with an introduction of the cellular mechanism of the diabetic ulcer. We will then discuss the strengths and limitations of various stem cell therapies that have been under extensive recent study.

\section{Diabetic Wound Healing}

Wound healing is a highly dynamic and complex process. When skin is injured, organic debris must be removed from the site of injury, and new components must be delivered or recreated there. These orchestrated processes involve mutual interactions between cells, extracellular matrix (ECM), and soluble factors $[8,9]$. Neovascularization is also a crucial step in this process [9]. However, diabetic wound healing shows impaired cellular activity, ECM synthesis, growth factor release, neovascularization, and so forth, resulting in ulcer formation [10-17]. Factors that contribute to delayed wound healing in diabetic patients are discussed as follows. Some other factors, such as infection and oxidative stress, however, will not be discussed either because they are less related to stem cell therapy or because seldom any publication is available to address them.

\section{Impaired Cellular Activity}

Many cell lineages are involved in wound healing. Fortyeight hours after injury, keratinocytes migrate from stratum 
basale and differentiate to form new skin [18]. Usui et al. evaluated proliferation, differentiation, adhesion, and migration of keratinocytes along the margin of chronic ulcers from patients with diabetes mellitus. Compared with a normal wound healing, keratinocytes from the diabetic ulcer exhibited increased proliferation, decreased differentiation, and decreased migration ability. They concluded that the decreased migratory ability of keratinocytes from diabetic patients may contribute to the slow wound healing process [18]. Fibroblasts contribute to wound healing by synthesizing collagen to increase the strength of the wound [19]. However, in the diabetic wound, fibroblasts are found to have several abnormal characteristics, including less proliferation and excessive apoptosis $[19,20]$. These diabetic fibroblasts also have impaired migration ability. It has been found that fibroblasts from diabetic mice migrate $75 \%$ less than those from normoglycemic mice. In addition, these epidermal cells have defective responses to growth factors and hypoxia, a condition commonly present in chronic wounds, which may also contribute to delayed wound healing in diabetic patients $[10,11,21]$.

Aside from these defective differentiated cells, abnormal stem cells also play a role in stalling wound healing. In a study of rat diabetic wound, Zhong et al. found that epidermal stem cells isolated from diabetic wounds showed decreased clone formation ability. By further examining the expression of beta-catenin and cyclin D1, these stem cells were found to be defective in the differentiation ability [12]. Adipose-derived stem cells (ADSCs), the stem cell in subcutaneous tissue, have also been studied. Differing from the aforementioned cells, ADSCs from both diabetic wounds and normal skin secreted identical amounts of growth factors, cytokines, and type I collagen. Diabetic ADSCs even proliferate at the same rate as those from normal wound healing [13]. These characteristics of ADSCs from diabetic wounds render them a potential cell source for wound healing and regeneration.

\section{ECM Synthesis}

ECM, composed of collagen, cell-adhesive glycoproteins, glycosaminoglycans, and proteoglycans, helps support cells and comprise key components of the basement membrane that anchors and helps replenish epidermal cells in normal skin. During wound healing, extracellular matrix components are active in each phase, interacting with cells and growth factors in a dynamic give and take that eventually results in wound closure [14]. Not only does it provide a scaffold for wound healing and regeneration, but also components of the ECM play key roles in stimulating cell proliferation and differentiation, guiding cell migration, and modulating cellular responses $[8,9]$. The diabetic wound is characterized by deficient ECM synthesis and excessive ECM degradation. Deficient ECM synthesis is attributed to impaired fibroblast activity [22]. The excessive ECM degradation is a result of increased matrix metalloproteinase (MMP) production [20]. Deficiency of collagen, the main component of ECM, results in chronic connective tissue defects and impaired wound healing $[15,23]$.

\section{Growth Factor Release}

During wound healing, growth factors released from platelets, macrophages, neutrophils, fibroblasts, keratinocytes, and endothelial cells influence every phase of wound healing by providing signals for various cellular activities. Epidermal growth factor (EGF), platelet-derived growth factor (PDGF), transforming growth factor-beta (TGF-beta), insulin-like growth factor 1 (IGF-1) vascular endothelial growth factor (VEGF), and fibroblast growth factor (FGF), are under intensive study. They are found to be closely related to epidermal cell proliferation, and some of them have been found to play an important role in angiogenesis by modulating endothelial cell migration and proliferation [24-28]. The diabetic wound is characterized by a reduced expression of nearly all of these growth factors [16].

\section{Angiogenesis and Neovascularization}

Angiogenesis and neovascularization are also an important part of wound healing. Angiogenesis refers to the sprouting of microvessels through a preexisting capillary network, whereas neovascularization refers to vascular formation from endothelial progenitor cells that differentiate or endothelial cells that proliferate in situ [29]. Not only do they provide nutrition and oxygen for wound healing, but also they bring inflammatory cells and circulating stem cells into the wound site. However, microcirculation damage is observed in diabetic wound healing $[17,30]$. Multiple factors are involved in the damage of vascular supply. Recent studies show that damaged microcirculation in the diabetic wound is caused by endothelial dysfunction [17, 30]. Other studies suggest that low levels of VEGF as well as senesce in endothelial progenitor cells (EPCs) may also play a role in decreased local neovascularization during diabetic wound healing [31].

\section{Inflammation}

Inflammation is a necessary part of normal wound healing, playing an important role in fighting infection, clearing debris, and inducing cell proliferation [8]. However, if prolonged, it can also lead to extra tissue damage, a phenomenon observed in diabetic wounds [32]. Studies show that prolonged inflammation in diabetic wounds is characterized by sustained expression of proinflammatory cytokines, such as interleukin-1 (IL-1) and TNF-alpha, and large numbers of polymorphonuclear neutrophils and macrophages, which delay epidermidalization [32]. Moreover, prolonged inflammation also leads to increased levels of MMPs, a family of proteases that can degrade the extracellular matrix proteins. During normal wound healing, various members of the MMP family are upregulated, and each of them cleaves a specific subset of matrix proteins. For example, MMP-9 can degrade proteins in the basal lamina and release keratinocytes to contribute to wound healing. However, misregulated expression of MMPs is found to contribute to impaired wound healing $[8,9]$. In a clinical study of diabetic wound, by comparing the patients who achieved complete wound healing and those who developed diabetic ulcers, the authors found that both 
increased inflammation and expression of MMPs, especially MMP-9, are the main factors that contribute to diabetic ulcer formation [33]. Ibuki et al. found that the skin is fragile in diabetic mice, which is caused by the increased levels of oxidative stress and MMPs [34]. Moreover, the abnormal expression of MMPs also contributes to the ineffectiveness of exogenous growth factor therapy [33-36].

\section{Stem Cell Therapy}

Stem cells are considered the master cells, capable of both self-renewal and multilineage differentiation [37]. Stem cell therapy, which refers to an interventional strategy that introduces adult stem cells into damaged tissue in order to treat disease or injury, has been studied as a treatment for diabetic ulcers [37]. Because of ethical problems associated with embryonic stem cells, we will focus on adult stem cell therapies, including mesenchymal stem cells (MSCs), endothelial progenitor cells (EPCs), bone-marrow-derived mononuclear cells (BM-MNCs), and fibrocytes (Table 1).

\section{Mesenchymal Stem Cells}

Mesenchymal stem cells (MSCs) are multipotent stromal cells that were first found in bone marrow by Friedenstein et al. in 1966 [38]. MSCs were later found in various other tissue types, including bone marrow, umbilical cord blood, adipose tissue, and amniotic membrane. There is no consensus on the characterization of these mesenchymal stem cells. The criterion proposed by the Mesenchymal and Tissue Stem Cell Committee of the International Society for Cellular Therapy is commonly used in research. According to this criterion, MSCs must be plastic adherent when maintained in standard culture conditions. MSCs must express CD105, CD73, and CD90 and lack expression of CD45, CD34, CD14 or CD11b, CD79alpha or CD19, and HLA-DR surface molecules. MSCs must be able to differentiate into osteoblasts, adipocytes, and chondroblasts in vitro [39]. Mesenchymal stem cells are the most common stem cell in clinical and basic science studies. Their multidirectional differentiation, easy collection, and weak immunogenicity make them a good source for therapy [40]. Various studies show that MSC transplantation can have multiple effects on diabetic wound healing, including promoting cell proliferation, collagen synthesis, growth factor release, wound contraction, neovascularization, and cellular recruitment to wounds [41].

Bone-marrow-derived mesenchymal stem cells (BMMSCs), also known as marrow stromal cells, are fibroblastlike self-renewing stem cells in the bone marrow [40]. The BM-MSCs are nearly $10 \%$ of the hematopoietic stem cells (HSCs) in number, and they are always regarded as a component of the HSC niche [37].

In a rat diabetic wound healing model, Kwon et al. found that systemic and local treatment with BM-MSCs on diabetic wounds improved the breaking strength by increasing collagen levels (types I-V) in the wound bed [42]. Higher expression of various growth factors has also been observed in numerous studies, including EGF, KGF, TGF-betal, VEGF,
SDGF-1alpha, IGF-1, IL-8, PDGF, and angiopoietin-1 [18$21,42]$. These growth factors contribute to the repair, the regeneration, and the neovascularization in the diabetic wound. One interesting finding about these growth factors is that in addition to their role in vascularization in situ, they can also recruit stem cells from the circulation or even from bone marrow to participate in angiogenesis [43]. Now, growing evidence shows that paracrine secretion of growth factors is the main therapeutic mechanism of these stem cells [28]. Another possible mechanism may be their direct transdifferentiation into vascular endothelial cells and skin components [44-46]. However, due to the low engraftment after transplantation and lower rate of differentiation in vivo, this mechanism is considered less important than the paracrine secretion effect $[33,41]$.

ADSCs have been referred to as processed lipoaspirate cells (PLA), adipose-derived stromal cells, and adiposederived mesenchymal progenitor cells. The nomenclature differences also reflect a lack of consensus and an evolving knowledge of the phenotype and function of these cells. Although the phenotype characterization of ADSCs generally follows the criteria proposed by the International Society for Cellular Therapy, some disputes still exist, especially the question that whether ADSCs are CD34 positive or negative [47, 48]. Both CD34+ and CD34-ADSCs have been considered as ADSCs [49]. Several recent studies show that CD34+ ADSCs have a greater proliferative capacity, while CD34- ADSCs have a greater differentiating capacity $[47,49$, 50].

Kim et al. studied the effect of human adipose-derived stem cells on healing of ischemic wounds in diabetic nude mice. The authors found that ADSC-treated animals had an earlier and abundant neovessel formation and better tissue remodeling than the control group without any treatment. Lower rates of autoamputation and a survival rate comparable to group II were also observed in the ADSC-treated group [51]. In an in vitro study, Lee et al. used human ADSC culture medium to treat human keratinocytes and dermal fibroblasts. The authors found increased cell proliferation in both cell types. Moreover, the expression of collagen I was also increased [47].

MSCs have been applied clinically for the treatment of diabetic wounds. Despite significant beneficial results, an in vitro expansion time is still in need to acquire a sufficient amount of cells for treatment. Long in vitro expansion time and multiple handling procedures are barriers for its clinical application and increase chances of infection [52].

\section{Endothelial Progenitor Cells}

EPCs were first isolated from peripheral blood and are characterized by expression of CD34, KDR (VEGFR-2), and CD133 markers. Later, EPCs were also found in bone marrow and umbilical cord blood [29].

There are studies showing that EPCs can be recruited from bone marrow or peripheral blood to the sites of neovascularization to participate in various normal and pathological processes, including wound healing and ischemic injury [53]. Studies have also been performed to evaluate therapeutic 
TABLE 1: Stem cells and their therapeutic effects.

\begin{tabular}{|c|c|c|}
\hline Cell type & Cell markers & Therapeutic effect \\
\hline BM-MSCs & $\begin{array}{l}\text { CD105+, CD73+, CD90+, CD45-, CD34-, CD14-, CD11b-, } \\
\text { CD79 alpha, CD19-, and HLA-DR- [37-39] }\end{array}$ & $\begin{array}{l}\text { Promote cell proliferation, collagen synthesis, growth factor } \\
\text { release, wound contraction, neovascularization, and cellular } \\
\text { recruitment to wounds [41-46]. }\end{array}$ \\
\hline ADSCs & $\begin{array}{l}\text { CD31-, CD34+/-, CD45-, CD90+, CD105-, and CD146- } \\
{[47-50]}\end{array}$ & $\begin{array}{l}\text { Increase cell proliferation, collagen synthesis, promote } \\
\text { neovessel formation, and tissue remodeling }[47,51,52]\end{array}$ \\
\hline EPCs & CD34+, VEGFR-2+, and CD133+ $[29,40]$ & $\begin{array}{l}\text { Promote vascularization secrete proangiogenic growth } \\
\text { factors and cytokines, and differentiate into endothelial cells } \\
\text { [53-55]. }\end{array}$ \\
\hline BMNCs & $\begin{array}{l}\text { hematopoietic progenitor cell markers: CD133+, CD117+, and } \\
\text { CD34 } \\
\text { MSCs markers and endothelial progenitor population: } \\
\text { CD34+/-, CD133+, and VEGFR2+ }[56,57]\end{array}$ & $\begin{array}{l}\text { Secrete angiogenic growth factors decrease local } \\
\text { inflammation, and promote vascularization differentiate into } \\
\text { endothelial cells [58-63]. }\end{array}$ \\
\hline Fibrocytes & $\begin{array}{l}\mathrm{CD} 34+, \mathrm{CD} 11 \mathrm{~b}+, \mathrm{CD} 13+, \mathrm{MHC} \mathrm{II}+, \mathrm{CD} 86+, \mathrm{CD} 45+\text {, } \\
\text { collagen-1+, procollagen-1+, CD3-, CD } 4-, \mathrm{CD} 8-, \mathrm{CD} 19-\text {, } \\
\text { and CD25- }[64,65]\end{array}$ & $\begin{array}{l}\text { Increasing cell proliferation ECM deposition, wound } \\
\text { contraction, and vascularization. } \\
\text { Secrete of growth factors and chemokines [65-70]. }\end{array}$ \\
\hline
\end{tabular}

potential of EPCs in diabetic wound healing. In a mouse wound healing model, Lee at al. [54] found that EPCs can promote wound healing and neovascularization. In their study, embryonic-stem-cell- (hESC-) derived EPCs were used for wound healing. Rapid reformation of granulation tissue and reepithelialization of wounds were observed after treatment. By further exploration of therapeutic mechanism, they found higher expression of EGF, bFGF, fractalkine, granulocyte-macrophage colony-stimulating factor (GMCSF), interleukin (IL)-6, IL-8, platelet-derived growth factorAA (PDGF-AA), and VEGF. They proposed that the therapeutic mechanism might be the secretion of growth factors and cytokines [54]. Besides their paracrine secretory effect, EPCs also have potential to differentiate into endothelial cells. Moreover, in some studies of ischemic injury, EPCs were found to migrate to the ischemic area from peripheral blood and even bone marrow $[29,55]$. The clinical application of EPCs also experiences similar problem as MSCs [52].

\section{Bone-Marrow-Derived Mononuclear Cells}

BM-MNCs are a group cells composed of many kinds of stem cells and differentiated cells, including hematopoietic stem cells, mesenchymal stem cells, endothelial progenitor cells, precursor cells, and their progeny [56]. MNCs are abundant in both peripheral blood and bone marrow, and they can be collected directly for transplantation without in vitro expansion [56].

As complex cell fractions, BM-MNCs have multiple cell markers. The most important cell populations involved in angiogenesis are hematopoietic progenitor cells (CD133+, CD117+, and CD34+) and MSCs, which are CD34 negative. Among MSCs, the endothelial progenitor population, composed chiefly of CD34-/CD133+/VEGFR2+ and CD34+/CD133+/VEGFR2+ cells, plays the most important role in vascular regeneration process [57].

In a diabetic mouse wound healing model, SivanLoukianova et al. found that during a five-day observation period, treatment with MNCs could accelerate epidermal healing and rapidly and dramatically accelerate revascularization of the wounds. During the initial treatment period, increased vascularization was mediated principally by an increase in vessel diameter. Later, both an increase in vessel size and number were observed [58]. There are also some clinical studies about MNC therapy: Ruiz-Salmeron et al. performed autologous MNC transplantation in diabetic patients with peripheral artery disease. After 3 to 12 months, all patients exhibited clinical improvement with a significant increase in vascular network [59]. Similar improvements have been observed in other clinical trials $[60,61]$. However, the therapeutic mechanism remains unclear. Some studies show that the elevated expression of angiogenic growth factors is observed after MNC transplantation. Other studies suggest that MNC transplantation can decrease local inflammation [45]. One study shows that a small portion of MNCs may differentiate into endothelial cells, indicating direct contribution to neovascularization $[56,62,63]$. The complex makeup of MNCs makes it difficult to further elucidate the therapeutic mechanism. Despite this, the avoidance of in vitro expansion makes MNCs practical for clinical application.

\section{Fibrocytes}

The "fibrocyte" was described in 1994 as a circulating, bonemarrow-derived cell with the ability to adopt a mesenchymal phenotype [64]. Fibrocytes are mostly found in peripheral blood, and they comprise $0.1 \%$ to $0.5 \%$ of the total leukocyte population [65]. They exhibit spindle-shaped morphology when cultured in vitro. This cell bears features of both fibroblasts and monocytes, and this combination of connective tissue cell and myeloid features allows its identification by a number of markers, such as CD34, CD11b+, CD13+, MHC II+, CD86+, and CD45+. They are also positive for some stromal cell markers such as collagen I, vimentin, and fibronectin $[65,66]$. Some studies show fibrocytes promote wound healing by increasing ECM deposition, wound contraction, 
TABLE 2: Clinical trials of stem cell therapy on the treatment of diabetic ulcer.

\begin{tabular}{|c|c|c|c|}
\hline Clinical trial & $\begin{array}{l}\text { Diabetic } \\
\text { cases }\end{array}$ & $\begin{array}{l}\text { Stem cell } \\
\text { therapy }\end{array}$ & Efficacy assessment \\
\hline Kirana et al. 2012 [71] & 24 & $\begin{array}{l}\text { BM-MSCs/BM- } \\
\text { MNCs }\end{array}$ & $80 \%$ cases achieved significant improvement. \\
\hline Ravari et al. 2011 [60] & 8 & BM-MNCs & Complete wound healing in 3 cases and significant improvement in 5 cases. \\
\hline Jain et al. $2011[72]$ & 25 & BM-MNCs & The rate of chronic lower extremity wound healing increased. \\
\hline Dash et al. 2009 [73] & 12 & BM-MSCs & $\begin{array}{l}\text { Significant improvement in pain-free walking distance and reduction in ulcer } \\
\text { size. }\end{array}$ \\
\hline Rogers et al. 2008 [74] & 3 & BM-MNCs & Good wound healing. \\
\hline Yoshikawa et al. 2008 [75] & 20 & MSCs & The wound mostly healed in 18 of the 20 patients. \\
\hline Kirana et al. 2007 [61] & 1 & BM-MNCs & Complete wound healing achieved. \\
\hline Badiavas et al. 2007 [76] & 4 & BM-MNCs & Complete wound healing achieved. \\
\hline Falanga et al. 2007 [77] & 8 & MSCs & All wounds healed completely between weeks 7 and 8 after the surgery. \\
\hline Asai et al. 2006 [78] & 1 & $\begin{array}{l}\text { BM-MNCs and } \\
\text { bFGF }\end{array}$ & Complete wound healing. \\
\hline Humpert et al. 2005 [79] & 2 & BM-MNCs & $\begin{array}{l}\text { Reduction of wound size and markedly increased vascularization were } \\
\text { achieved. }\end{array}$ \\
\hline Vojtassák et al. 2006 [80] & 1 & $\begin{array}{l}\text { Fibroblast and } \\
\text { MSCs }\end{array}$ & Closing and healing of the nonhealing diabetic ulcer was achieved. \\
\hline Badiavas and Falanga $2003[81]$ & 3 & BM-MNCs & Dermal rebuilding and closure of nonhealing chronic wounds were achieved. \\
\hline
\end{tabular}

and vascularization [67]. After local injection of fibrocytes, Kao et al. found that these cells can accelerate wound healing by stimulating cell proliferation, reepithelialization, and angiogenesis [67]. Higher expression of growth factors (VEGF, b-FGF, TGF-beta, PDGF-A, and FGF-7), chemokines (MCP-1 and MIP-1alpha), and extracellular matrix (collagen I and alpha-SMA) was observed in fibrocyte-treated wounds, suggesting that the paracrine secretion effect of fibrocytes might contribute to diabetic wound healing $[65,67,68]$. The in vivo differentiation of fibrocytes has remained unclear. Some studies suggest that fibrocytes may contribute to wound healing by differentiating into fibroblasts and myoblasts [69]. However, other studies suggest that fibrocytes are mesenchymal progenitors and can differentiate into mesenchymal stem cells in vivo [70]. Further studies are needed to explore the therapeutic potential of these cells.

\section{Conclusions}

The diabetic ulcer remains an important clinical challenge in the current medical practice, and much effort has been focused on the development of novel therapeutic approaches for its treatment. Various stem cell therapies have shown promise, and pertinent clinical trials are summarized in Table 2. Stem cell transplantation can provide systemic improvement to the wound site, including enhancement in cell proliferation, ECM synthesis, growth factor release, and neovascularization. Transplanted stem cells can act as a "biological pump" to secrete various growth factors. They can also contribute to wound healing by differentiating into skin or vascular components. Despite their great therapeutic potential, some questions still remain. First, most of these cells, except MNCs, need in vitro expansion to acquire sufficient numbers, greatly limiting clinical application. Second, most stem cell therapies, for clinical use, are achieved through autologous transplantation. That brings up the issue that whether stem cells isolated from diabetic patients are still "normal" and whether there is some method to reprogram them to "normal." Some research shows that diabetic EPCs are functionally impaired, possibly requiring as of yet undescribed methods to restore them to normal $[79,82]$. Finally, there is still concern that these stem cells may not be oncologically safe as some studies show that stem cells may contribute to tumor growth or even become the source of tumors [83, 84]. Further study is needed to answer these questions and to make stem cell therapies more practical in the clinical setting.
Abbreviations
ECM:
Extracellular matrix
ADSCs: $\quad$ Adipose-derived stem cells
MMP: $\quad$ Matrix metallo proteinase
EGF: $\quad$ Epidermal growth factor
PDGF: Platelet-derived growth factor
TGF-beta: Transforming growth factor-beta
IGF-1: $\quad$ Insulin-like growth factor 1
VEGF: Vascular endothelial growth factor
FGF: $\quad$ Fibroblast growth factor
KGF: Keratinocyte growth factor
SDGF-1alpha: Stromal cell-derived factor-1 alpha
IL-8: $\quad$ Interleukin-8
GM-CSF: Granulocyte-macrophage
colony-stimulating factor
EPCs: Endothelial progenitor cells
MSCs: Mesenchymal stem cells
BM-MNCs: Bone-marrow-derived mononuclear cells
MCP-1: $\quad$ Monocyte chemotactic protein-1
MIPs: Macrophage inflammatory proteins. 


\section{Acknowledgment}

The authors appreciate Nathan Wetter Taylor's help with the language editing.

\section{References}

[1] R. Eldor, I. Raz, A. B. Yehuda, and A. J. M. Boulton, "New and experimental approaches to treatment of diabetic foot ulcers: a comprehensive review of emerging treatment strategies," Diabetic Medicine, vol. 21, no. 11, pp. 1161-1173, 2004.

[2] P. R. Cavanagh, B. A. Lipsky, A. W. Bradbury, and G. Botek, "Treatment for diabetic foot ulcers," The Lancet, vol. 366, no. 9498, pp. 1725-1735, 2005.

[3] J. P. Hong and S. W. Park, "The combined effect of recombinant human epidermal growth factor and erythropoietin on fullthickness wound healing in diabetic rat model," International Wound Journal, 2012.

[4] T. Dinh, F. Tecilazich, A. Kafanas et al., "Mechanisms involved in the development and healing of diabetic foot ulceration," Diabetes, vol. 61, no. 11, pp. 2937-2947, 2012.

[5] H. Brem and M. Tomic-Canic, "Cellular and molecular basis of wound healing in diabetes," Journal of Clinical Investigation, vol. 117, no. 5, pp. 1219-1222, 2007.

[6] N. B. Menke, K. R. Ward, T. M. Witten, D. G. Bonchev, and R. F. Diegelmann, "Impaired wound healing," Clinics in Dermatology, vol. 25, no. 1, pp. 19-25, 2007.

[7] M. Yang, Q. Li, L. Sheng, H. Li et al., "Bone marrowderived mesenchymal stem cells transplantation accelerates tissue expansion by promoting skin regeneration during expansion," Annals of Surgery, vol. 253, no. 1, pp. 202-209, 2011.

[8] P. Martin, "Wound healing-aiming for perfect skin regeneration," Science, vol. 276, pp. 75-81, 1997.

[9] G. C. Gurtner, S. Werner, Y. Barrandon, and M. T. Longaker, "Wound repair and regeneration," Nature, vol. 453, no. 7193, pp. 314-321, 2008.

[10] M. V. Mendez, A. Stanley, T. Phillips et al., "Fibroblasts cultured from distal lower extremities in patients with venous reflux display cellular characteristics of senescence," Journal of Vascular Surgery, vol. 28, no. 6, pp. 1040-1050, 1998.

[11] K. Hehenberger and A. Hansson, "High glucose-induced growth factor resistance in human fibroblasts can be reversed by antioxidants and protein kinase C-inhibitors," Cell Biochemistry and Function, vol. 15, no. 3, pp. 197-201, 1997.

[12] Q. L. Zhong, F. R. Liu, D. W. Liu et al., "Expression of $\beta$-catenin and cyclin D1 in epidermal stem cells of diabetic rats," Molecular Medicine Reports, vol. 4, no. 2, pp. 377-381, 2011.

[13] M. Nambu, M. Ishihara, S. Kishimoto et al., "Stimulatory effect of autologous adipose tissue-derived stromal cells in an atelocollagen matrix on wound healing in diabetic $\mathrm{db} / \mathrm{db}$ mice," Journal of Tissue Engineering, vol. 2, no. 1, Article ID 158105, 2011.

[14] G. S. Schultz, J. M. Davidson, R. S. Kirsner, P. Bornstein, and I. M. Herman, "Dynamic reciprocity in the wound microenvironment," Wound Repair and Regeneration, vol. 19, no. 2, pp. 134148, 2011.

[15] S. M. Ayuk, N. N. Houreld, and H. Abrahamse, "Collagen production in diabetic wounded fibroblasts in response to lowintensity laser irradiation at $660 \mathrm{~nm}$," Diabetes Technology \& Therapeutics, vol. 14, no. 12, pp. 1110-1117, 2012.

[16] J. Berlanga-Acosta, "Diabetic lower extremity wounds: the rationale for growth factors-based infiltration treatment," International Wound Journal, vol. 8, no. 6, pp. 612-620, 2011.
[17] G. K. Kolluru, S. C. Bir, and C. G. Kevil, "Endothelial dysfunction and diabetes: effects on angiogenesis, vascular remodeling, and wound healing," International Journal of Vascular Medicine, vol. 2012, Article ID 918267, 30 pages, 2012.

[18] M. L. Usui, J. N. Mansbridge, W. G. Carter, M. Fujita, and J. E. Olerud, "Keratinocyte migration, proliferation, and differentiation in chronic ulcers from patients with diabetes and normal wounds," Journal of Histochemistry and Cytochemistry, vol. 56, no. 7, pp. 687-696, 2008.

[19] T. Desta, J. Li, T. Chino, and D. T. Graves, "Altered fibroblast proliferation and apoptosis in diabetic gingival wounds," Journal of Dental Research, vol. 89, no. 6, pp. 609-614, 2010.

[20] O. Z. Lerman, R. D. Galiano, M. Armour, J. P. Levine, and G. C. Gurtner, "Cellular dysfunction in the diabetic fibroblast: impairment in migration, vascular endothelial growth factor production, and response to hypoxia," American Journal of Pathology, vol. 162, no. 1, pp. 303-312, 2003.

[21] M. A. M. Loots, S. B. Kenter, F. L. Au et al., "Fibroblasts derived from chronic diabetic ulcers differ in their response to stimulation with EGF, IGF-I, bFGF and PDGF-AB compared to controls," European Journal of Cell Biology, vol. 81, no. 3, pp. 153-160, 2002.

[22] H. Lateef, M. J. Stevens, and J. Varani, "All-trans-retinoic acid suppresses matrix metalloproteinase activity and increases collagen synthesis in diabetic human skin in organ culture," American Journal of Pathology, vol. 165, no. 1, pp. 167-174, 2004.

[23] D. M. Bermudez, B. J. Herdrich, J. Xu et al., "Impaired biomechanical properties of diabetic skin: implications in pathogenesis of diabetic wound complications," American Journal of Pathology, vol. 178, no. 5, pp. 2215-2223, 2011.

[24] S. Y. Aghdam, S. A. Eming, S. Willenborg et al., "Vascular endothelial insulin/IGF-1 signaling controls skin wound vascularization," Biochemical and Biophysical Research Communications, vol. 421, no. 2, pp. 197-202, 2012.

[25] F. Cianfarani, G. Zambruno, L. Brogelli et al., "Placenta growth factor in diabetic wound healing: altered expression and therapeutic potential," American Journal of Pathology, vol. 169, no. 4, pp. 1167-1182, 2006.

[26] R. D. Galiano, O. M. Tepper, C. R. Pelo et al., "Topical vascular endothelial growth factor accelerates diabetic wound healing through increased angiogenesis and by mobilizing and recruiting bone marrow-derived cells," American Journal of Pathology, vol. 164, no. 6, pp. 1935-1947, 2004.

[27] E. K. Tiaka, N. Papanas, A. C. Manolakis et al., "Epidermal growth factor in the treatment of diabetic foot ulcers: an update," Perspectives in Vascular Surgery and Endovascular Therapy, vol. 24, no. 1, pp. 37-44, 2012.

[28] C. Peng, B. Chen, H. K. Kao et al., "Lack of FGF-7 further delays cutaneous wound healing in diabetic mice," Plastic and Reconstructive Surgery, vol. 128, no. 6, pp. 673e-684e, 2011.

[29] Q. Li and M. Yang, Stem Cell Research: A New Era for Reconstructive Surgery, 2012.

[30] H. Kämpfer, J. Pfeilschifter, and S. Frank, "Expressional regulation of angiopoietin- 1 and -2 and the Tie- 1 and -2 receptor tyrosine kinases during cutaneous wound healing: a comparative study of normal and impaired repair," Laboratory Investigation, vol. 81, no. 3, pp. 361-373, 2001.

[31] Z. J. Liu and O. C. Velazquez, "Hyperoxia, endothelial progenitor cell mobilization, and diabetic wound healing," Antioxidants and Redox Signaling, vol. 10, no. 11, pp. 1869-1882, 2008.

[32] S. Guo and L. A. DiPietro, "Factors affecting wound healing," Journal of Dental Research, vol. 89, no. 3, pp. 219-229, 2010. 
[33] T. Dinh, F. Tecilazich, A. Kafanas et al., "Mechanisms involved in the development and healing of diabetic foot ulceration," Diabetes, vol. 61, no. 11, pp. 2937-2947, 2012.

[34] A. Ibuki, T. Akase, T. Nagase et al., "Skin fragility in obese diabetic mice: possible involvement of elevated oxidative stress and upregulation of matrix metalloproteinases," Experimental Dermatology, vol. 21, no. 3, pp. 178-183, 2012.

[35] H. Ebaid, A. Salem, A. Sayed et al., "Whey protein enhances normal inflammatory responses during cutaneous wound healing in diabetic rats," Lipids in Health and Disease, vol. 10, article 235, 2011.

[36] C. Wetzler, H. Kampfer, B. Stallmeyer, J. Pfeilschifter, and S. Frank, "Large and sustained induction of chemokines during impaired wound healing in the genetically diabetic mouse: prolonged persistence of neutrophils and macrophages during the late phase of repair," Journal of Investigative Dermatology, vol. 115, no. 2, pp. 245-253, 2000.

[37] G. Ren, X. Chen, F. Dong et al., "Concise review:mesenchymal stem cells and translational medicine: emerging issues," Stem Cells Translational Medicine, vol. 1, no. 1, pp. 51-58, 2012.

[38] A. J. Friedenstein, I. I. Piatetzky-Shapiro, and K. V. Petrakova, "Osteogenesis in transplants of bone marrow cells," Journal of Embryology and Experimental Morphology, vol. 16, no. 3, pp. 381-390, 1966.

[39] M. Dominici, K. Le Blanc, I. Mueller et al., "Minimal criteria for defining multipotent mesenchymal stromal cells. The International Society for Cellular Therapy position statement," Cytotherapy, vol. 8, no. 4, pp. 315-317, 2006.

[40] M. Yang and Q. Li, "Cell transplantation and reconstructive surgery," in Tech: Cell Transplantation, p. 104, 89.

[41] A. M. Hocking and N. S. Gibran, "Mesenchymal stem cells: paracrine signaling and differentiation during cutaneous wound repair," Experimental Cell Research, vol. 316, no. 14, pp. 2213-2219, 2010.

[42] D. S. Kwon, X. Gao, Y. B. Liu et al., "Treatment with bone marrow-derived stromal cells accelerates wound healing in diabetic rats," International Wound Journal, vol. 5, no. 3, pp. 453463, 2008.

[43] L. Chen, E. E. Tredget, P. Y. G. Wu, Y. Wu, and Y. Wu, "Paracrine factors of mesenchymal stem cells recruit macrophages and endothelial lineage cells and enhance wound healing," PLoS ONE, vol. 3, no. 4, article e1886, Article ID e1886, 2008.

[44] S. W. Kim, H. Z. Zhang, L. Guo et al., "Amniotic mesenchymal stem cells enhance wound healing in diabetic NOD/SCID mice through high angiogenic and engraftment capabilities," PLoS One, vol. 7, no. 7, article e41105, 2012.

[45] Y. Wu, L. Chen, P. G. Scott, and E. E. Tredget, "Mesenchymal stem cells enhance wound healing through differentiation and angiogenesis," Stem Cells, vol. 25, no. 10, pp. 2648-2659, 2007.

[46] C. A. Uysal, R. Ogawa, F. Lu, H. Hyakusoku, and H. Mizuno, "Effect of mesenchymal stem cells on skin graft to flap prefabrication: an experimental study," Annals of Plastic Surgery, vol. 65, no. 2, pp. 237-244, 2010.

[47] S. H. Lee, S. Y. Jin, J. S. Song et al., "Paracrine effects of adiposederived stem cells on keratinocytes and dermal fibroblasts," Annals of Dermatology, vol. 24, no. 2, pp. 136-143, 2012.

[48] A. A. Nery, I. C. Nascimento, T. Glaser et al., "Human mesenchymal stem cells: from immunophenotyping by flow cytometry to clinical applications," Cytometry A, vol. 83, no. 1, pp. 4861, 2013.
[49] H. Mizuno, M. Tobita, and A. C. Uysal, "Concise review: adipose-derived stem cells as a novel tool for future regenerative medicine," Stem Cells, vol. 30, no. 5, pp. 804-810, 2012.

[50] A. M. Bailey, S. Kapur, and A. J. Katz, "Characterization of adipose-derived stem cells: an update," Current Stem Cell Research and Therapy, vol. 5, no. 2, pp. 95-102, 2010.

[51] E. K. Kim, G. Li, T. J. Lee et al., "The effect of human adiposederived stem cells on healing of ischemic wounds in a diabetic nude mouse model," Plastic and Reconstructive Surgery, vol. 128, no. 2, pp. 387-394, 2011.

[52] L. Sheng, M. Yang, Z. Du et al., "Transplantation of stromal vascular fraction as an alternative for accelerating tissue expansion," Journal of Plastic, Reconstructive \& Aesthetic Surgery, 2012.

[53] X. Deng, S. Szabo, L. Chen et al., "New cell therapy using bone marrow-derived stem cells/endothelial progenitor cells to accelerate neovascularization in healing of experimental ulcerative colitis," Current Pharmaceutical Design, vol. 17, no. 16, pp. 1643-1651, 2011.

[54] M. J. Lee, J. Kim, K. I. Lee, J. M. Shin, J. I. Chae, and H. M. Chung, "Enhancement of wound healing by secretory factors of endothelial precursor cells derived from human embryonic stem cells," Cytotherapy, vol. 13, no. 2, pp. 165-178, 2011.

[55] S. Park, O. M. Tepper, R. D. Galiano et al., "Selective recruitment of endothelial progenitor cells to ischemic tissues with increased neovascularization," Plastic and Reconstructive Surgery, vol. 113, no. 1, pp. 284-293, 2004.

[56] M. Yang, L. Sheng, H. Li, R. Weng, and Q. F. Li, "Improvement of the skin flap survival with the bone marrow-derived mononuclear cells transplantation in a rat model," Microsurgery, vol. 30, no. 4, pp. 275-281, 2010.

[57] M. P. Murphy, J. H. Lawson, B. M. Rapp et al., "Autologous bone marrow mononuclear cell therapy is safe and promotes amputation-free survival in patients with critical limb ischemia," Journal of Vascular Surgery, vol. 53, no. 6, pp. 1565.e11574.el, 2011

[58] E. Sivan-Loukianova, O. A. Awad, V. Stepanovic, J. Bickenbach, and G. C. Schatteman, "CD34+ blood cells accelerate vascularization and healing of diabetic mouse skin wounds," Journal of Vascular Research, vol. 40, no. 4, pp. 368-377, 2003.

[59] R. Ruiz-Salmeron, A. de la Cuesta-Diaz, M. ConstantinoBermejo et al., "Angiographic demonstration of neoangiogenesis after intra-arterial infusion of autologous bone marrow mononuclear cells in diabetic patients with critical limb ischemia," Cell Transplantation, vol. 20, no. 10, pp. 1629-1639, 2011.

[60] H. Ravari, D. Hamidi-Almadari, M. Salimifar, S. Bonakdaran, M. R. Parizadeh, and G. Koliakos, "Treatment of non-healing wounds with autologous bone marrow cells, platelets, fibrin glue and collagen matrix," Cytotherapy, vol. 13, no. 6, pp. 705-711, 2011.

[61] S. Kirana, B. Stratmann, D. Lammers et al., "Wound therapy with autologous bone marrow stem cells in diabetic patients with ischaemia-induced tissue ulcers affecting the lower limbs," International Journal of Clinical Practice, vol. 61, no. 4, pp. 690692, 2007.

[62] D. C. S. Pedroso, A. Tellechea, L. Moura et al., "Improved survival, vascular differentiation and wound healing potential of stem cells co-cultured with endothelial cells," PLoS ONE, vol. 6, no. 1, article e16114, 2011.

[63] Y. Okuno, A. Nakamura-Ishizu, K. Kishi, T. Suda, and Y. Kubota, "Bone marrow-derived cells serve as proangiogenic 
macrophages but not endothelial cells in wound healing," Blood, vol. 117, no. 19, pp. 5264-5272, 2011.

[64] R. Bucala, L. A. Spiegel, J. Chesney, M. Hogan, and A. Cerami, "Circulating fibrocytes define a new leukocyte subpopulation that mediates tissue repair," Molecular Medicine, vol. 1, no. 1, pp. 71-81, 1994.

[65] T. E. Quan, S. Cowper, S. P. Wu, L. K. Bockenstedt, and R. Bucala, "Circulating fibrocytes: collagen-secreting cells of the peripheral blood," International Journal of Biochemistry and Cell Biology, vol. 36, no. 4, pp. 598-606, 2004.

[66] E. L. Herzog and R. Bucala, "Fibrocytes in health and disease," Experimental Hematology, vol. 38, no. 7, pp. 548-556, 2010.

[67] H. K. Kao, B. Chen, G. F. Murphy et al., "Peripheral blood fibrocytes: enhancement of wound healing by cell proliferation, re-epithelialization, contraction, and angiogenesis," Annals of Surgery, vol. 254, no. 6, pp. 1066-1074, 2011.

[68] I. Hartlapp, R. Abe, R. W. Saeed et al., "Fibrocytes induce an angiogenic phenotype in cultured endothelial cells and promote angiogenesis in vivo," FASEB Journal, vol. 15, no. 12, pp. 22152224, 2001.

[69] J. F. Wang, H. Jiao, T. L. Stewart, H. A. Shankowsky, P. G. Scott, and E. E. Tredget, "Fibrocytes from burn patients regulate the activities of fibroblasts," Wound Repair and Regeneration, vol. 15, no. 1, pp. 113-121, 2007.

[70] A. Bellini and S. Mattoli, "The role of the fibrocyte, a bone marrow-derived mesenchymal progenitor, in reactive and reparative fibroses," Laboratory Investigation, vol. 87, no. 9, pp. 858-870, 2007.

[71] S. Kirana, B. Stratmann, C. Prante et al., "Autologous stem cell therapy in the treatment of limb ischaemia induced chronic tissue ulcers of diabetic foot patients," International Journal of Clinical Practice, vol. 66, no. 4, pp. 384-393, 2012.

[72] P. Jain, B. Perakath, M. R. Jesudason et al., "The effect of autologous bone marrow-derived cells on healing chronic lower extremity wounds: results of a randomized controlled study," Ostomy Wound Management, vol. 57, no. 7, pp. 38-44, 2011.

[73] N. R. Dash, S. N. Dash, P. Routray, S. Mohapatra, and P. C. Mohapatra, "Targeting nonhealing ulcers of lower extremity in human through autologous bone marrow-derived mesenchymal stem cells," Rejuvenation Research, vol. 12, no. 5, pp. 359366, 2009.

[74] L. C. Rogers, N. J. Bevilacqua, and D. G. Armstrong, "The use of marrow-derived stem cells to accelerate healing in chronic wounds," International Wound Journal, vol. 5, no. 1, pp. 20-25, 2008.

[75] T. Yoshikawa, H. Mitsuno, I. Nonaka et al., "Wound therapy by marrow mesenchymal cell transplantation," Plastic and Reconstructive Surgery, vol. 121, no. 3, pp. 860-877, 2008.

[76] E. V. Badiavas, D. Ford, P. Liu et al., "Long-term bone marrow culture and its clinical potential in chronic wound healing," Wound Repair and Regeneration, vol. 15, no. 6, pp. 856-865, 2007.

[77] V. Falanga, S. Iwamoto, M. Chartier et al., "Autologous bone marrow-derived cultured mesenchymal stem cells delivered in a fibrin spray accelerate healing in murine and human cutaneous wounds," Tissue Engineering, vol. 13, no. 6, pp. 1299-1312, 2007.

[78] J. Asai, H. Takenaka, K. Ichihashi, E. Ueda, N. Katoh, and S. Kishimoto, "Successful treatment of diabetic gangrene with topical application of a mixture of peripheral blood mononuclear cells and basic fibroblast growth factor," Journal of Dermatology, vol. 33, no. 5, pp. 349-352, 2006.
[79] P. M. Humpert, U. Bärtsch, I. Konrade et al., "Locally applied mononuclear bone marrow cells restore angiogenesis and promote wound healing in a type 2 diabetic patient," Experimental and Clinical Endocrinology \& Diabetes, vol. 113, no. 9, pp. 538540, 2005.

[80] J. Vojtassák, L. Danisovic, M. Kubes et al., "Autologous biograft and mesenchymal stem cells in treatment of the diabetic foot," Neuroendocrinology Letters, Supplement 2, pp. 134-137, 2006.

[81] E. V. Badiavas and V. Falanga, "Treatment of chronic wounds with bone marrow-derived cells," Archives of Dermatology, vol. 139, no. 4, pp. 510-516, 2003.

[82] C. J. M. Loomans, E. J. P. De Koning, F. J. T. Staal et al., "Endothelial progenitor cell dysfunction: a novel concept in the pathogenesis of vascular complications of type 1 diabetes," Diabetes, vol. 53, no. 1, pp. 195-199, 2004.

[83] M. Zhao, P. C. Sachs, X. Wang et al., "Mesenchymal stem cells in mammary adipose tissue stimulate progression of breast cancer resembling the basal-type," Cancer Biology \& Therapy, vol. 13, no. 9, pp. 782-792, 2012.

[84] I. Martin-Padura, G. Gregato, P. Marighetti et al., "The white adipose tissue used in lipotransfer procedures is a rich reservoir of CD34+ progenitors able to promote cancer progression," Cancer Research, vol. 72, no. 1, pp. 325-334, 2012. 


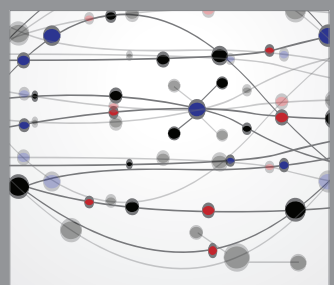

The Scientific World Journal
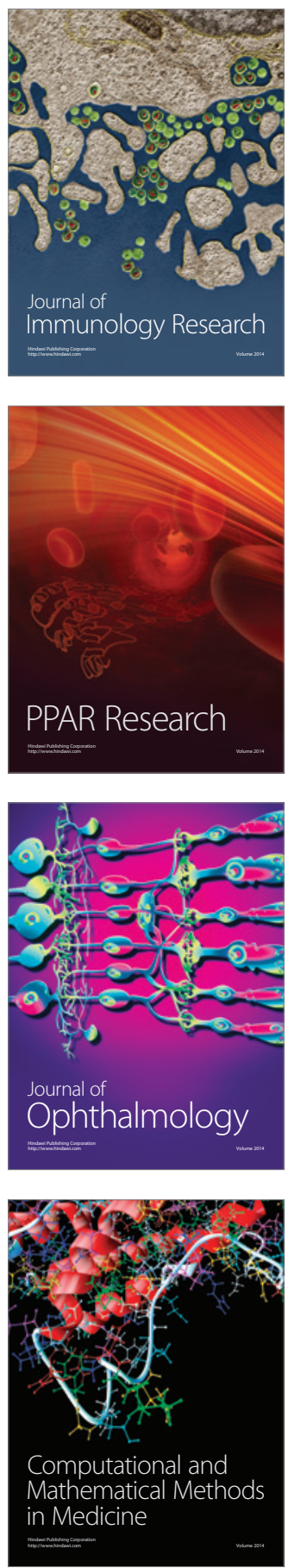

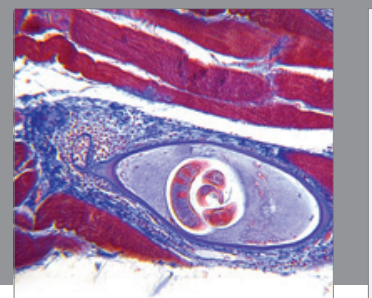

Gastroenterology

Research and Practice
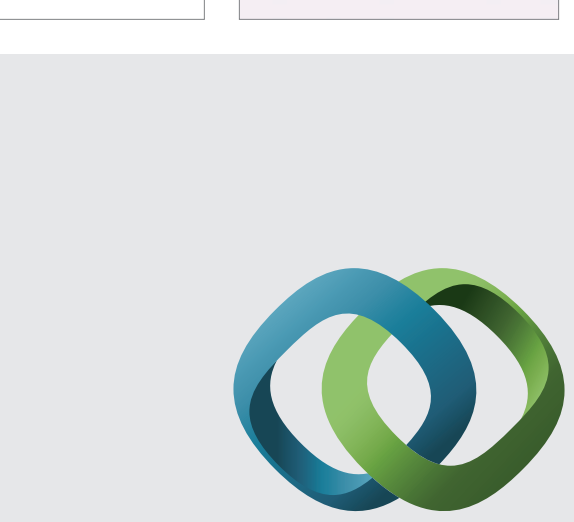

\section{Hindawi}

Submit your manuscripts at

http://www.hindawi.com
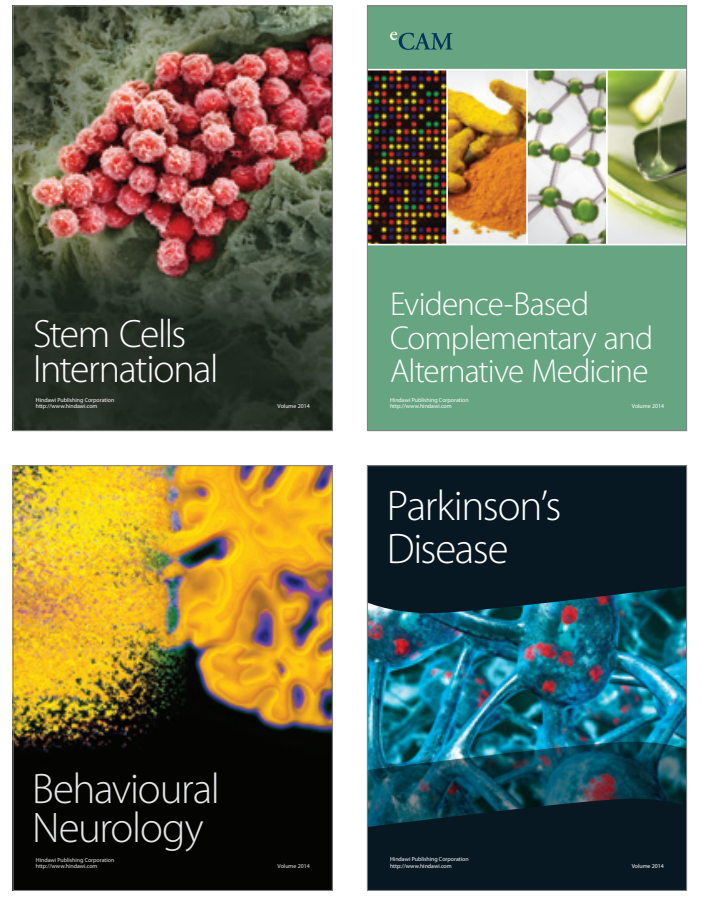
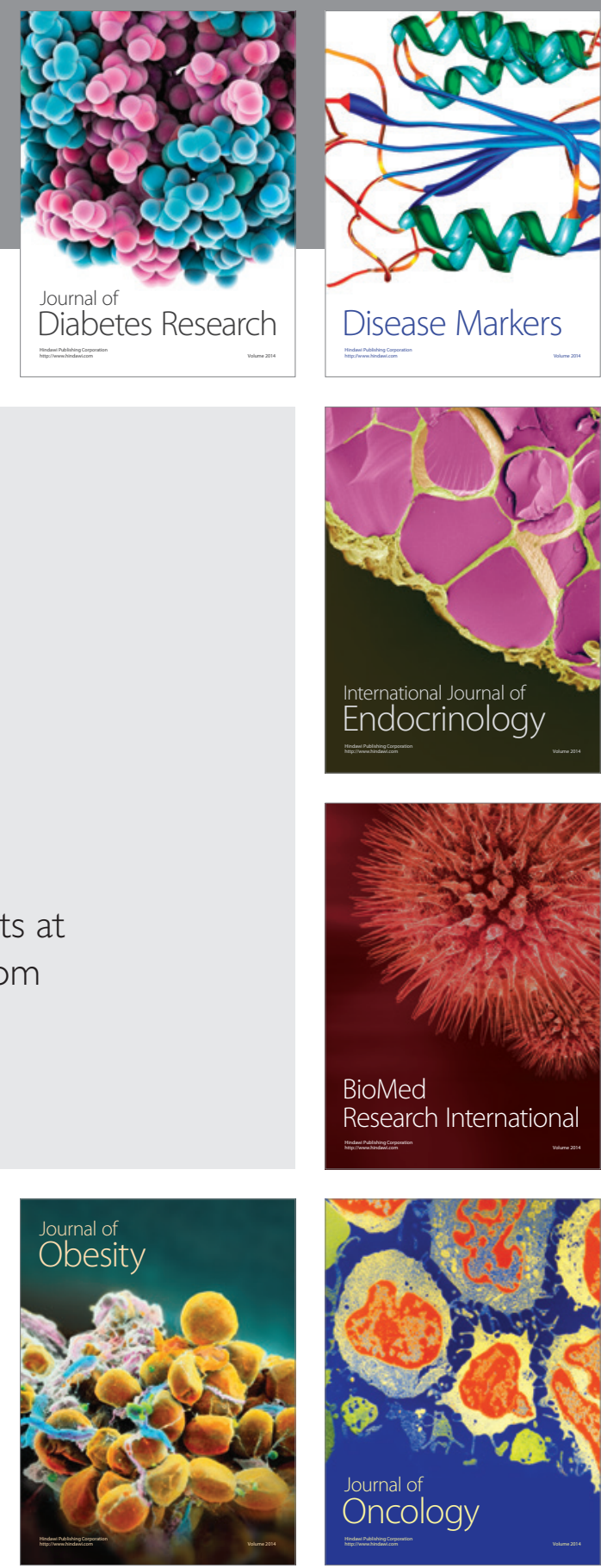

Disease Markers
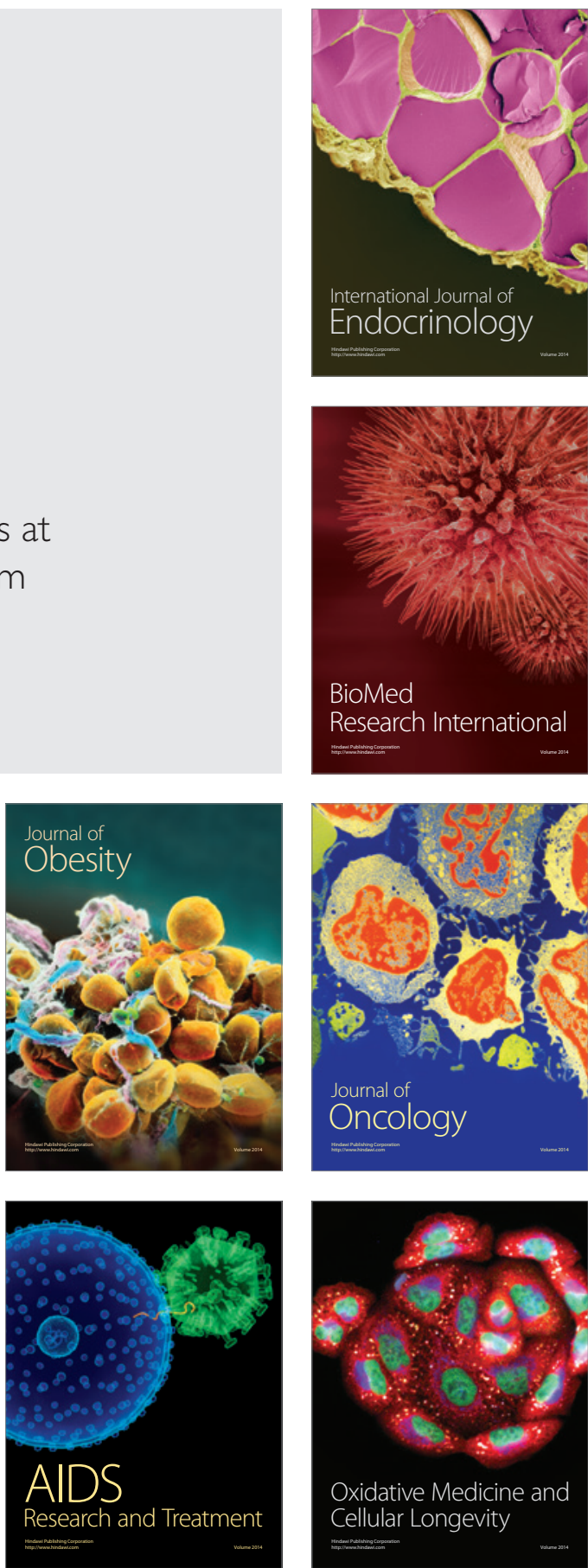